\title{
Ellen E. Bowen: Domestic violence treatment for abusive women-a treatment manual
}

\author{
Routledge Press, 214 pages
}

\author{
Gail Erlick Robinson
}

Published online: 13 July 2010

(C) Springer-Verlag 2010

According to the author, this book is designed to provide mental health professionals with a framework for understanding women's domestic violence as well as directions for structuring and facilitating groups for abusive women. The book is divided into two parts, an overview of domestic violence with specific emphasis on women as aggressors and a manual providing details on how to establish a treatment program for women. The programs described are based on the authors' years of clinical experience working with violent women.

In the shorter Part 1, the author challenges the argument that women are primarily the victims of domestic violence, citing studies that report women being the aggressors as often as men. Men may also be more reluctant to report domestic violence. Violent women may be aggressors, victims who fight back, or participants in a mutually hostile relationship. While women may be violent as often as men, they are injured more than men. Men tend to hit or beat their partners while women tend to slap, throw objects, or use verbal or psychological aggression. The author seems to believe that women's reproductive hormone changes predispose them to violent emotions - a disputable fact.

Bowne gives a general overview of the etiology of domestic violence including family of origin, social learning theory, attachment theory, and the effects on the brain of early trauma. All of these are described in quite brief, simplistic terms. She uses a motivational interviewing way of assessing readiness for change and stages of change. The treatment is essentially aimed at getting the woman to stop the violence and take responsibility for her role. Bowen

\section{G. E. Robinson $(\square)$}

Department of Psychiatry,

University of Toronto,

Toronto, Canada

e-mail: gail.robinson@utoronto.ca notes that, when there is no state law prohibiting concurrent couples' therapy (put in place to prevent angry partners from becoming more abusive), this might be helpful.

The Practice section of the book gives a very detailed account of how to structure groups for women. The underlying theme is that this treatment program is specifically designed for women, not merely a slightly altered version of that used for men. Information about the initial assessments is given, including samples of appointment letters, intake forms, rules of the program, information regarding confidentiality, and a consent to treatment. Bowen describes the specific situations that might arise, such as the woman bringing her children to the interview or appearing drunk, and discusses how to handle these situations.

This section continues to give a precise, step-by-step outline of how to set up groups, facilitate a discussion, and even keep accurate records. Throughout, Bowen gives many examples of possible difficulties that a therapist might encounter and even scripts of how to handle these situations. There are also copies of numerous handouts covering such issues as "time outs", "tranquility breathing", "emotional inventory", "how to do journal homework", "jealousy", "forgiveness" - a total of 28 handouts covering a wide range of relevant subjects. With each handout is a brief note for the therapist describing the theme of that handout and suggesting ways of using it. Finally, there is an appendix containing references for therapists and clients including books, media, websites, and support groups.

This book is short and easily readable. While the theory section may be slight and many will disagree with the author's view of the frequency of female aggressors, I know of no other manual that is so complete and detailed in its instruction as to how to set up and conduct such a group. Whether or not there are large numbers of such female aggressors, this is still a useful tool for treating such women. 